www.jmscr.igmpublication.org

Index Copernicus Value: 79.54

ISSN (e)-2347-176x ISSN (p) 2455-0450

crossref DOI: https://dx.doi.org/10.18535/jmscr/v7i4.106

\title{
Comparison of Post Operative Recovery Characteristics with Isoflurane and Sevoflurane in Patients Undergoing Laparoscopic Cholecystectomy: A Randomised Control Study
}

\author{
Authors \\ Raja Avinash $^{1}$, Praveen Kumar Singh ${ }^{2}$, Priyesh Kumar ${ }^{3}$, Ravi Kant $^{3}$ \\ ${ }^{1}$ Senior Resident, Indira Gandhi Institute of Medical Sciences, Patna, Bihar, India \\ ${ }^{2 *}$ Senior Resident, Shree Krishna Medical College \& Hospital, Muzaffarpur, Bihar, India \\ ${ }^{3}$ Junior Resident, Indira Gandhi Institute of Medical Sciences, Patna, Bihar, India \\ *Corresponding Author \\ Dr Praveen Kumar Singh \\ Email:Praveen_pks@yahoo.com
}

\begin{abstract}
Background: Inhaled volatile anesthetic remains the most widely used drug for the maintenance of general anesthesia. These volatile anesthetic namely isoflurane, sevoflurane are in current practice for maintenance of anesthesia. Management of haemodynamic stability is the most important part of standardized balanced technique.

Material \& Methods: The study was conducted in IGIMS, Patna and SKMCH, Muzaffarpur. The study was prospective and randomized, conducted in indoor patients belonging to either sex, after obtaining informed consent from each patient. Most of the patients are from urban population. Sixty ASA physical status I-II patients of either sex, aged 35-70 years and weighing 40-70 kg, scheduled for elective laparoscopic cholecystectomy under general anesthesia were randomly divided into three groups - group A and B with equal numbers

Results: We compared the recovery time after closing the inhalational agent isoflurane or sevoflurane. It was assess by eye opening, hand grip, extubation and answering name. It is less for Sevoflurane than Isoflurane.

Conclusion: In elective laparoscopic cholecystectomy operations agent of choice for maintenance of anesthesia will be sevoflurane followed by isoflurane according to early recovery characteristics.
\end{abstract}

\section{Introduction}

Inhaled volatile anesthetic remains the most widely used drug for the maintenance of general anesthesia. This is because of the ease of administration and predictable intraoperative and recovery characteristics.
Over the past years, there have been three gases and thirteen volatile anesthetic agents made available for clinical use. The majority have fallen by the way side as a consequence of their various side-effects. Nitrous oxide, diethyl ether, and chloroform were the earliest inhalational anesthetics. Subsequently drugs still available for 
clinical uses are - Halothane, Isoflurane, Sevoflurane and Desflurane.

Nitrous oxide was first recognized as an analgesic in the early $19^{\text {th }}$ century, but it's low potency precludes its use as the sole anesthetic agent for most procedures.

Isoflurane was first used clinically in 1981. It is a good, general purpose anesthetic and is probably the most widely used currently. Metabolism to other potential toxic substances is minimal. It produces less depression of the cardiovascular system and is fairly potent. However, as a sole agent it produces tachycardia and vasodilation, particularly in younger patients.

New inhaled anesthetics; desflurane was introduced in 1992 and was followed in 1994 by sevoflurane. Their low blood solubility provides more precise control over the delivery of anesthesia, and more rapid recovery at the end of anesthesia independent of their duration of administration.

Sevoflurane; its advantage over isoflurane is the pleasant odor which makes it the agent of choice for gas induction. Unlike other agents, however, concerns have been made about sevoflurane interaction with carbon dioxide absorbers.

These volatile anesthetic namely isoflurane, sevoflurane are in current practice for maintenance of anesthesia. Management of haemodynamic stability is the most important part of standardized balanced technique.

Post operative recovery is the most important aspect to look for in standardized balanced anaesthesia technique with volatile anesthetics.

The study was done to evaluate post operative recovery characteristics in laparoscopic cholecystectomy patients with diffirent volatile anesthetic agents namely isoflurane and sevoflurane.

\section{Aims and Objectives}

The purpose of this study was to evaluate comparatively post operative recovery characteristics of patients undergoing laparoscopic cholecystectomy with isoflurane, and sevoflurane as volatile anesthetic agent for maintenance of anesthesia.

Following parameters are used as markers of post operative recovery:

Early recovery characteristics:

- Eye opening.

- Hand grip.

- Tracheal extubation.

- Name.

Delayed recovery characteristics:

- PACU discharge criteria (fast tracking score)

\section{Materials and Methods}

The study was conducted in IGIMS, Patna and SKMCH, Muzaffarpur.

The study was prospective and randomized, conducted in indoor patients belonging to either sex, after obtaining informed consent from each patient. Most of the patients are from urban population. Sixty ASA physical status I-II patients of either sex, aged 35-70 years and weighing 40$70 \mathrm{~kg}$, scheduled for elective laparoscopic cholecystectomy under general anesthesia were randomly divided into three groups - group A and $B$ with equal numbers $(n=30)$.

Group A received Isoflurane as maintenance volatile anesthetic agent in $60 \% \mathrm{~N} 2 \mathrm{O}, \mathrm{O} 2$ anesthesia.

Group B received Sevoflurane as maintenance volatile anesthetic agent in $60 \% \mathrm{~N} 2 \mathrm{O}, \mathrm{O} 2$ anesthesia.

$\begin{array}{ll}\text { Group - } & \text { Study drug- } \\ \text { A } & \text { Isoflurane-0.6\% } \\ \text { B } & \text { Sevoflurane-1\% }\end{array}$

\section{Exclusions from the study}

Patients were excluded from the study, if they had:

1) History of allergic reaction to drugs,

2) Any evidence of major cardiovascular, pulmonary, hepatic, renal, endocrine, metabolic, neurologic and psychiatric diseases.

3) Patients chronically receiving sedative medication. 


\section{Preparation of patients}

After fasting for at least 6 hours, patients received Tablet Midazolam $7.5 \mathrm{mg}$ orally 1 hour before induction.

\section{Anesthesia Technique}

All operations were performed under general anesthesia with controlled ventilation.

In the operative room, a $18 \mathrm{G}$ I.V cannula was inserted and crystalloid started. Monitoring included pulse oximetry, non-invasive blood pressure, 3 lead standard electrocardiogram (ECG), end-tidal carbon dioxide (ETCO2) and end-tidal inhalational gas. After induction with Fentanyl $3 \mu \mathrm{g} / \mathrm{kg}$ and Propofol $2-2.5 \mathrm{mg} / \mathrm{kg}$ I.V in a titrated dose till loss of eye lash reflex, patients were intubated following vecuronium $0.1 \mathrm{mg} / \mathrm{kg}$ I.V and connected to circle absorber system. For maintenance patients received either isoflurane $0.6 \%$ or sevoflurane $1 \%$ with nitrous oxide $60 \%$ in oxygen. ETCO2 was maintained between 30-40 mmHg, MAP and H.R within $20 \%$ of preinduction baseline values. If MAP or H.R. remained increased for $5 \mathrm{~min}$; additional dose of fentanyl $(0.5 \mu \mathrm{g} / \mathrm{kg})$ was given. If H.R. dropped below 45 beats per minute, atropine $0.3 \mathrm{mg} \mathrm{I.V}$ was given. Intraoperative hypotension was treated with intraoperative fluid loss replacement. If not responsive, then anesthetic concentration was decreased. Muscle relaxation was maintained with vecuronium 1/10th the intubating dose at 30 minute interval.

The time of discontinuation of anesthetic agent was considered time end for all measurements.

\section{Assessment}

The following parameters were noted intraoperatively-

A. Patient characteristics

- Age

- Weight

- Gender (male/female)

- ASA I / II

B.Following parameters are used as markers of post operative recovery:

1. Early recovery characteristics:
- Eye opening.

- Hand grip.

- Tracheal extubation.

- Name.

2. Delayed recovery characteristics:

- PACU discharge criteria ( fast tracking score)

Demographic data of patients understudy in each group were compared. Though HR, SBP, DBP and MAP were noted at baseline, after intubation, before incision and 5 minutes thereafter, but only $\mathrm{HR}$ and MAP at baseline, after intubation, before incision and 10 minutes thereafter till 50 minutes were considered for statistical analysis and comparison. This was done to make the study simple, technically easy, but reliable.

Though hypertension response to intubation had been included in statistical analysis and graphical representation, it is not the objective the study.

Criteria Used to Determine Fast Tracking (PACU Discharge Criteria) PA

\begin{tabular}{|c|c|}
\hline Criteria & Score \\
\hline \multicolumn{2}{|l|}{ Level of Consciousness } \\
\hline Awake and oriented & 2 \\
\hline Arousable with minimal stimulation & 1 \\
\hline Responsive only to tactile stimulation & 0 \\
\hline \multicolumn{2}{|l|}{ Physical Activity } \\
\hline Able to move all extremities on command & 2 \\
\hline Some weakness in movement of the extremities & 1 \\
\hline Unable to voluntarily move the extremities & 0 \\
\hline \multicolumn{2}{|l|}{ Hemodynamic Stability } \\
\hline Blood pressure $<15 \%$ of the baseline MAP value & 2 \\
\hline $\begin{array}{l}\text { Blood pressure between } 15 \% \text { and } 30 \% \text { of the baseline } \\
\text { MAP value }\end{array}$ & 1 \\
\hline Blood pressure $>30 \%$ below the baseline MAP value & 0 \\
\hline \multicolumn{2}{|l|}{ Respiratory Stability } \\
\hline Able to breathe deeply & 2 \\
\hline Tachypnea with good cough & 1 \\
\hline Dyspneic with weak cough & 0 \\
\hline \multicolumn{2}{|l|}{ Oxygen Saturation Status } \\
\hline Maintains value $>90 \%$ on room air & 2 \\
\hline Requires supplemental oxygen (nasal prongs) & 1 \\
\hline Saturation < $90 \%$ with supplemental oxygen & 0 \\
\hline \multicolumn{2}{|l|}{ Postoperative Pain Assessment } \\
\hline None or mild discomfort & 2 \\
\hline Moderate to severe pain controlled with IV analgesics & 1 \\
\hline Persistent severe pain & 0 \\
\hline \multicolumn{2}{|l|}{ Postoperative Emetic Symptoms } \\
\hline None or mild nausea with no active vomiting & 2 \\
\hline Transient vomiting or retching & 1 \\
\hline Persistent moderate to severe nausea and vomiting & 0 \\
\hline Total score & 14 \\
\hline
\end{tabular}


From White PF, Song D: New criteria for fasttracking after outpatient anesthesia: A comparison with the modified Aldrete's scoring system. Anesth Analg 88:1069, 1999.

A score over 12 with no individual score less than 1 is required for fast-tracking.

Observations And Results

\section{Demographic characteristics}

Age Distribution

Table 1:

\begin{tabular}{|l|c|c|}
\hline & $\begin{array}{c}\text { Sevoflurane } \\
(\mathbf{B})\end{array}$ & $\begin{array}{c}\text { Isoflurane } \\
(\mathbf{A})\end{array}$ \\
\hline Age (yrs) & $53.4 \pm 6.92$ & $50.86 \pm 3.66$ \\
\hline
\end{tabular}

\section{Sex Distribution}

Table 2

\begin{tabular}{|l|c|c|}
\hline & $\begin{array}{c}\text { Sevoflurane } \\
(\mathbf{B})\end{array}$ & $\begin{array}{c}\text { Isoflurane } \\
(\mathbf{A})\end{array}$ \\
\hline $\begin{array}{l}\text { Sex } \\
\text { (Male:Female) }\end{array}$ & $18: 12$ & $14: 16$ \\
\hline
\end{tabular}

\section{Weight Distribution}

\section{Table 3}

\begin{tabular}{|l|c|c|}
\hline & $\begin{array}{c}\text { Sevoflurane } \\
\text { (B) }\end{array}$ & $\begin{array}{c}\text { Isoflurane } \\
\text { (A) }\end{array}$ \\
\hline $\begin{array}{l}\text { Weight } \\
\text { (in Kgs) }\end{array}$ & $56.8 \pm 7.07$ & $54.5 \pm 3.93$ \\
\hline
\end{tabular}

\section{Height Distribution}

Table 4:

\begin{tabular}{|l|c|c|}
\hline & $\begin{array}{c}\text { Sevoflurane } \\
\text { (B) }\end{array}$ & $\begin{array}{c}\text { Isoflurane } \\
(\mathbf{A})\end{array}$ \\
\hline Height $(\mathrm{cms})$ & $158.33 \pm 7.46$ & $157.2 \pm 6.74$ \\
\hline
\end{tabular}

\section{ASA Classification}

\section{Table 5:}

\begin{tabular}{|l|c|c|}
\hline & $\begin{array}{c}\text { Sevoflurane } \\
(\mathbf{B})\end{array}$ & $\begin{array}{c}\text { Isoflurane } \\
(\mathbf{C})\end{array}$ \\
\hline ASA class & $13: 17$ & $14: 16$ \\
(I:II) & & \\
\hline
\end{tabular}

\section{Post operative recovery characteristic}

Table 6: Early Recovery Time (sec) in two groups

\begin{tabular}{|c|c|c|c|c|}
\hline & $\begin{array}{c}\text { Sevoflurane } \\
\text { (B) }\end{array}$ & $\begin{array}{l}\text { Isoflurane } \\
\text { (A ) }\end{array}$ & p-value & \multirow{5}{*}{$\begin{array}{l}\text { Kruskal-wallis test is } \\
\text { used because assumption } \\
\text { of normality (for } \\
\text { ANOVA) is violated in } \\
\text { these variables }\end{array}$} \\
\hline Eye Opening & $122.87 \pm 2.5$ & $181.33 \pm 2.07$ & $<0.0001$ & \\
\hline Hand grip & $179.2 \pm 18.07$ & $242.07 \pm 1.93$ & $<0.0001$ & \\
\hline Tracheal extubation & $323.07 \pm 3.93$ & $483.67 \pm 5.56$ & $<0.0001$ & \\
\hline Name & $425.73 \pm 8.78$ & $546.53 \pm 9.55$ & $<0.0001$ & \\
\hline
\end{tabular}

Table 7: PACU Monitoring

\begin{tabular}{|c|c|c|c|c|}
\hline $\begin{array}{l}\text { Fast tracking } \\
\text { Score }\end{array}$ & $\begin{array}{l}\text { Sevoflurane } \\
\text { (B) }\end{array}$ & $\begin{array}{l}\text { Isoflurane } \\
\text { (A) }\end{array}$ & p-value & \multirow{8}{*}{$\begin{array}{l}\text { Kruskal-wallis test } \\
\text { is used because } \\
\text { assumption of } \\
\text { normality (for } \\
\text { ANOVA) is } \\
\text { violated in these } \\
\text { variables }\end{array}$} \\
\hline $0 \mathrm{~min}$ & $4.07 \pm 0.58$ & $2.33 \pm 0.75$ & $<0.0001$ & \\
\hline $15 \mathrm{~min}$ & $5.8 \pm 0.8$ & $4.23 \pm 0.77$ & $<0.0001$ & \\
\hline $30 \mathrm{~min}$ & $7.67 \pm 0.71$ & $5.87 \pm 0.73$ & $<0.0001$ & \\
\hline $45 \mathrm{~min}$ & $9.17 \pm 0.95$ & $7.67 \pm 0.88$ & $<0.0001$ & \\
\hline 60min & $10.87 \pm 1$ & $9.43 \pm 0.97$ & $<0.0001$ & \\
\hline $75 \mathrm{~min}$ & $12.43 \pm 0.82$ & $11.47 \pm 0.9$ & $<0.0001$ & \\
\hline $90 \mathrm{~min}$ & Score for all is 14 & $13.93 \pm 0.25$ & & \\
\hline
\end{tabular}

\section{Discussion}

Isoflurane is a halogenated methyl ethyl ether (2, 2, 2, - trifluoro-1-chloroethyl-difluoro methyl ether). Sevoflurane is a fluorinated methyl isopropyl ether (2, 2, 2, - trifluoro-1-[trifluoro methyl] - ether).

\section{Salient features}

- Halogenation reduces flammability.

- Alkanes precipitate arrhythmias.

- Trifluoro carbon groups add stability.

- Fluorination reduces solubility and also potency. 
- Complete fluorination also results in a high vapor pressure, because of less intermolecular attraction.

\begin{tabular}{|l|l|c|c|}
\hline & & Isoflurane & Sevoflurane \\
\hline 1. & Molecular weight & 184 & 200 \\
\hline 2. & SVP (20 C) & 238 & 157 \\
\hline 3. & Boiling Point (C) & 49 & 59 \\
\hline 4. & Blood Gas Coefficient & 1.4 & 0.60 \\
\hline 5. & Brain Blood Solubility & 1.6 & 1.7 \\
\hline 6. & Fat : Blood Solubility & 44.9 & 47.5 \\
\hline 7. & $\begin{array}{l}\text { Muscle: Blood } \\
\text { Solubility }\end{array}$ & 2.9 & 3.1 \\
\hline 8. & MAC (100\% $\left.\mathrm{O}_{2}\right)$ & 1.17 & 1.8 \\
\hline 9. & MAC (60-70\% $\left.\mathrm{N}_{2} \mathrm{O}\right)$ & 0.56 & 0.66 \\
\hline 10. & Flammability $(\%)$ & $?$ & 10 \\
\hline 11. & $\begin{array}{l}\text { Stability in CO } \\
\text { Absorber }\end{array}$ & YES & NO (COMP A) \\
\hline 12. & Physical Properties & $\begin{array}{c}\text { Colorless, } \\
\text { Slight } \\
\text { pungent }\end{array}$ & $\begin{array}{c}\text { Clear, colorless } \\
\text { with Sweet smell }\end{array}$ \\
\hline
\end{tabular}

\section{Physiochemical Properties}

Rise in alveolar concentration $\left(\mathrm{F}_{\mathrm{A}}\right)$ is most rapid with less soluble agents (sevoflurane) than for more soluble agents (halothane). This ensures prompt induction of anesthesia and recovery after discontinuation of anesthetic. Sevoflurane has little or no respiratory irritant properties and may be used to rapidly induced anesthesia. Desflurane and sevoflurane provide one specific advantage over other currently available potent inhaled anesthetics. Their lower blood and tissue solubilities permit more precise control over the induction of anesthesia and more rapid recovery when the drug is discontinued. Most of the other properties of these new volatile anesthetics resemble their predecessors, especially at concentrations of less than or equal to 1 MAC.

\section{Mechanism of Action}

Inhaled anesthetics ablate movement in response to noxious stimuli by depressing spinal cord functions, whereas their amnesic actions are mediated within the brain.

\section{Inhalation anesthetics}

1. Disrupts the transmission throughout the CNS.

2. Disrupts synaptic transmission more readily than axonal.
3. May block excitatory (viz $\mathrm{Ca}$ \& Glutamate) and enhance inhibitory transmission.

4. Interfere with the presynaptic release and re-uptake of neurotransmitters.

5. Interfere with postsynaptic binding and ionic conductance.

\section{Biotransformation}

Only $0.2 \%$ of isoflurane undergoes oxidative metabolism by cytochrome P-450 enzymes in the liver. The major metabolites are trifluoroacetic acid and fluoride ion. However, the quantities are insufficient to cause minimal cell damage . Minimal metabolism of isoflurane reflects the drug's chemical stability and low solubility in tissues such that the drug is exhaled unchanged, rather than repeatedly passing through the liver.

Sevoflurane, less than $5 \%$ is metabolized in the liver to form organic and inorganic metabolites, which are rapidly excreted in the urine. Studies designed to evaluate fluoride- induced toxicity have failed to demonstrate renal injury with sevoflurane despite prolonged anesthesia.

The study was prospective as all parameters were noted after the treatment was given. It was randomized by randomly allocating the patients in two groups. In our study, regarding age, height, weight, ASA physical status and sex there was no significant difference between the groups (P>0.05)- ( ref. table I, II, III ).

The number of patients in each group were equal $(n=30)$, so impact of age, height, weight, ASA physical status and sex; if any, was equal in all the groups. In our study we used isoflurane $0.6 \%$, and sevoflurane $1 \%$ in $60 \% \mathrm{~N}_{2} \mathrm{O}$ anesthesia. These are equipotent mixture and about $1 \mathrm{MAC}$ in $\mathrm{N}_{2} \mathrm{O}$ anesthesia.

\section{Summary}

This was a randamised, prospective and double blinded study performed in 60 patients with 30 patients in each group undergoing elective laparoscopic cholecystectomy. 
Group A received Isoflurane as inhalational agent, Group B received Sevoflurane as inhalational agent in elective laparoscopic cholecystectomy of ASA I and II patients.

The main parameters studied were Early and Delayed post operative recovery characteristics.

To summarise the findings of our study:

1) There was no statistically significant difference between the three groups in respect to demographic parameters like age,sex, weight and height.

2) On comparing early post operative recovery characteristics Sevoflurane group has the earliest recovery followed by the isoflurane group.

3) On comparing the delayed recovery characteristics too Sevoflurane group has the earliest recovery followed by the Isoflurane group.

4) None of the patients have any intraoperative and post operative hemodynamic or airway related problems.

5) All the three drugs can be used for maintenance of anesthesia in laparoscopic cholecystectomy operations.

6) Baseline parameters in all the three groups are same and comparable.

\section{Conclusion}

Based on our study results we can say both the volatile anesthetic agents can be used for maintenance of anesthesia in elective laparoscopic cholecystectomy operations of ASA I and II patients. All maintains good hemodynamic parameters and airway intraoperatively and post operatively.

But Sevoflurane has earliest recovery than isoflurane.

Hence, based on our study we can recommend that in elective laparoscopic cholecystectomy operations agent of choice for maintenance of anesthesia will be sevoflurane followed by isoflurane according to early recovery characteristics.

\section{Bibliography}

1. Comparison of Recovery Profile After Ambulatory Anesthesia with Propofol, Isoflurane, Sevoflurane and Desflurane: A Systematic Review. Gupta, Anil, MD, FRCA, $\mathrm{PhD}^{* \dagger}$; Stierer, Tracey, MD*; Zuckerman, Rhonda, MD*; Sakima, Neal, MD*; Parker, Stephen D., MD*; Fleisher, Lee A., MD*

2. Anesthesia for laparoscopic cholecystectomy: comparative evaluation--desflurane/ sevoflurane vs. propofol. Erk $\mathrm{G}^{1}$, Erdogan G, Sahin F, Taspinar V, Dikmen B.

3. Target Controlled Infusion versus Sevoflurane/Desflurane Anesthesia for Laparoscopic Cholecystectomy: Comparison Postoperative Nausea/Vomiting and Extubation Time. Prathep S, Mahattanaporn S, Wasinwong W. J Med Assoc Thai. 2015 Dec;98(12):1187-92.PMID: 27004303

4. The impact of isoflurane, desflurane, or sevoflurane on the frequency and severity of postoperative nausea and vomiting after lumbar disc surgery. Wallenborn $\mathbf{J}^{1}$, Rudolph C, Gelbrich G, Goerlich TM, Helm J, Olthoff D.

5. Sevoflurane: an ideal agent for adult day-case anesthesia? Ghatge S, Lee J, Smith I.Acta Anaesthesiol Scand. 2003 Sep; 47(8):917-31.

6. Randomized, controlled trial comparing the effects of anesthesia with propofol, isoflurane, desflurane and sevoflurane on pain after laparoscopic cholecystectomy. Ortiz $\mathrm{J}^{1}$, Chang $\quad \mathrm{LC}^{2}$, Tolpin $\quad \mathrm{DA}^{2}$, Minard $\mathrm{CG}^{3}$, Scott $\mathrm{BG}^{4}$, Rivers $\mathrm{JM}^{2}$.

7. Comparison of recovery profile for propofol and sevoflurane anesthesia in cases of open cholecystectomy. Shiv Kumar Singh, Amit Kumar, Reena Mahajan, Surabhi Katyal, ${ }^{1}$ and Sfurti Mann. 